http://jmscr.igmpublication.org/home/ ISSN (e)-2347-176x ISSN (p) 2455-0450 crossref DOI: https://dx.doi.org/10.18535/jmscr/v8i4.38

\title{
Various Foreign Body Encoutered in Aerodigestive Tract in ENT Practices: A Case Series
}

\author{
Authors \\ Dr Deepak Parmar ${ }^{1}$, Dr V.P. Narve (M.S.) ${ }^{2 *}$, Dr Vinay Gangwani (M.S.) ${ }^{3}$ \\ ${ }^{1}$ RSO, Dept. of ENT, GRMC Gwalior \\ ${ }^{2}$ Professor \& HOD, Dept of ENT, GRMC Gwalior \\ ${ }^{3}$ Senior Resident, Dept of ENT Gwalior \\ *Corresponding Author \\ Dr V.P. Narve (M.S.)
}

\begin{abstract}
Foreign body ingestion or aspiration is one of commonest emergency encountered by otorhinolarngologists. It occurs more commonly in children, and may be the cause of morbidity and complications. The purpose of this study is to diagnose and manage aero-digestive foreign bodies in infants with unusual presentation and no definite history. All patients presented to our Otorhinolaryngology Department with symptoms unresponsive to medical treatment and patients with no definite history of foreign body aspiration were prospectively evaluated and all patients underwent proper management and foreign body removal.
\end{abstract}

\section{Introduction}

A foreign body is a piece of extraneous matter incongruous with the anatomy of site of lodgement. It may be classified as animate or inanimate (corrosive/non corrosive), organic or inorganic, hydrophobic or hydrophilic ${ }^{[1]}$.

Foreign bodies in Ear, Nose and Throat are one of the most common presentation that otorhinolarnyngologists meet with in their career, carrying significant mortality and morbidity if not diagnosed and managed promptly. Foreign body aspiration (FB) is leading cause of accidental death in children ${ }^{[2]}$.

It is estimated that 1,000 children die annually in the USA because of FB aspiration ${ }^{[3]}$. But in our country incidence may be much more because of poverty and illiteracy, though no such data available.

The type, shape, size and location of the foreign body determines its necessity of an emergency removal $^{[1]}$.

It is commonest in children between 9 months and 3 years of age because: (a) exploration of their environment by putting objects into their mouths; (b) learning to walk and run; (c) inadequate dentition; (d) immature swallowing coordination; and (e) supervision by an older sibling ${ }^{[4]}$.

\section{Case 1}

A 50 yrs old male.

Complaining of:

Difficulty in swallowing since 5 hours

Foreign body sensation in throat since 5 hours 
History of :

Accidental ingestion of denture during meal.

Difficulty in breathing

Change in voice

\section{Examination}

Ear: NAD, Nose: NAD,

\section{Mouth and Throat: NAD}

\section{Videolaryngoscopy}

Shows an unsual foreign body (oral denture) at the level of laryngeal inlet.

\section{Investigations}

Blood Routine: Normal

\section{Treatment}

Hypopharyngoscopy and removal of foreign body done under I.V. sedation

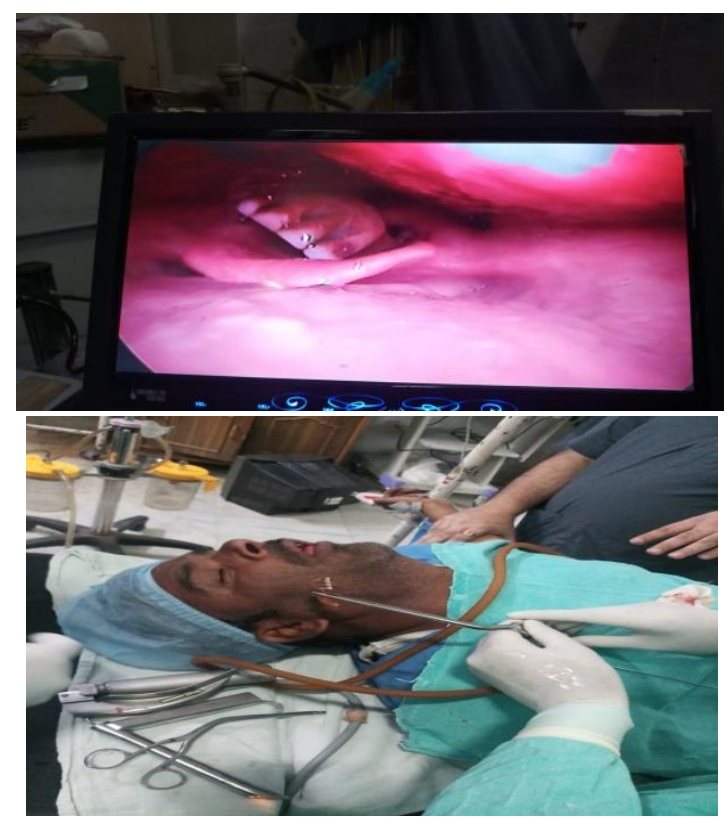

\section{Case 2}

A 6 months female.

Complaining of: (history given by father)

Recurrent bouts of vomiting after feed since 1 day.

History of :

Accidental ingestion of crystal bead (kancha).

No history of difficulty in breathing

X ray Neck, Chest and Abdomen (AP \& Lateral View)

Shows an circular radio opaque foreign body at the level c4 vertebrae.

\section{Investigations}

Blood Routine: Normal

\section{Treatment}

Laryngoscopy and removal of foreign body done under i.v. sedation.

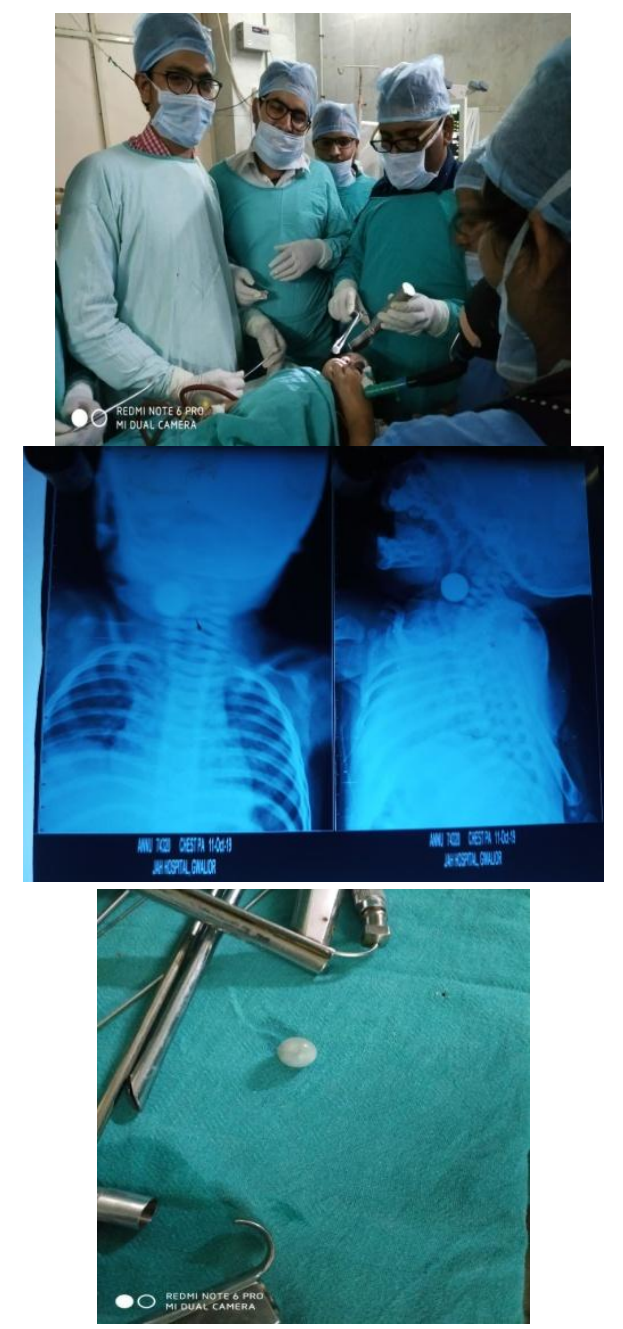

\section{Case 3}

A 1.5 year female.

Complaining of: (history given by father)

Recurrent bouts of vomiting after feed since 5 hours.

History of :

Accidental ingestion of metallic foreign body (RAKHI) while playing.

No history of difficulty in breathing

$X$ ray Neck, Chest and Upper Abdomen (AP \& Lateral View)

Shows an circular radio opaque foreign body with pointed margins all around (RAKHI) at the level of cricopharynx. 


\section{JMSCR Vol||08||Issue||04||Page 195-199||April}

\section{Investigations}

Blood Routine: Normal

\section{Treatment}

Hypopharyngoscopy and removal of foreign body done under i.v. sedation.

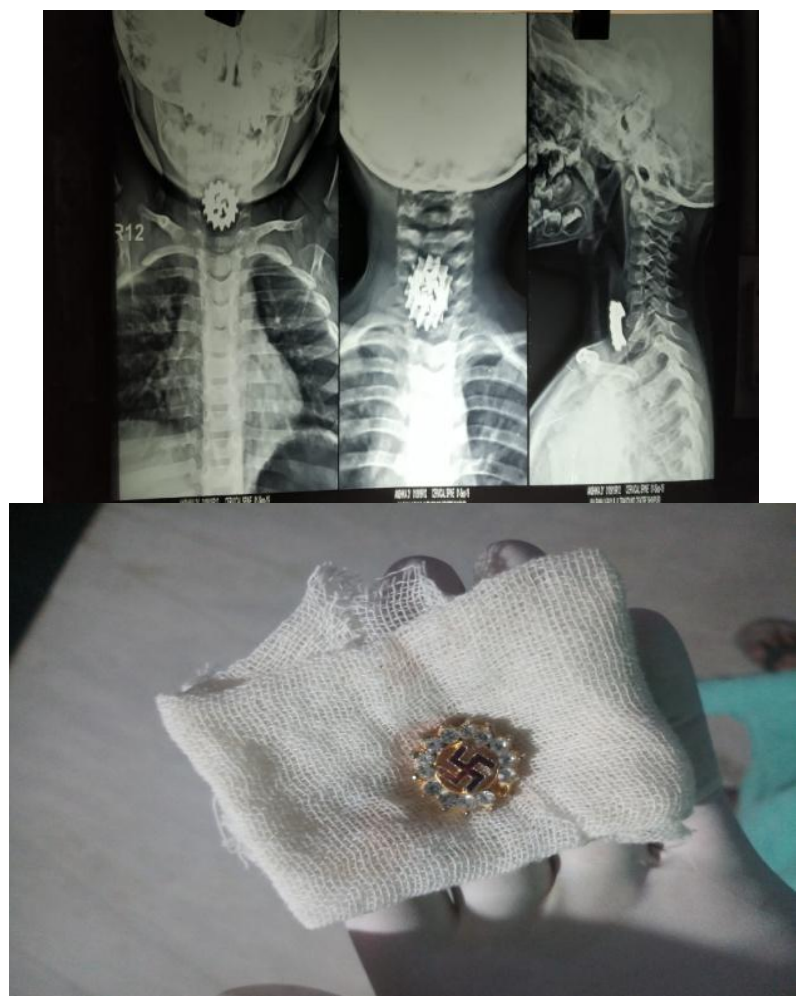

\section{CASE 4}

A 2 year male.

Complaining of:

Recurrent bouts of vomiting since 4 months

History of:

Treatment since last 4 months as infection, malaria, liver problems since last 4 months but not relieved.

\section{Examination}

Ear: NAD

Nose: NAD

Mouth and Throat: NAD

$X$ ray Neck, Chest and Abdomen (AP \& Lateral View)

Shows an circular radio opaque foreign body at the lower half of oesophagous

\section{Investigations}

Blood Routine: Normal

\section{Treatment}

oesophagoscopy and removal of foreign body (battery) done under G.A.

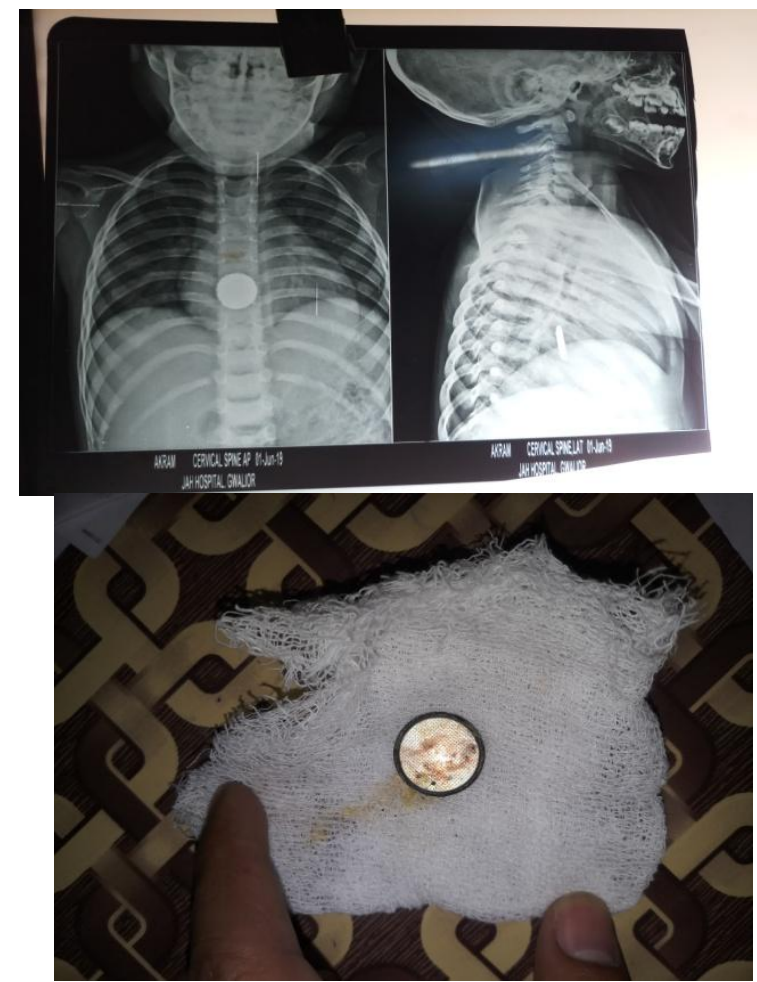

Case 5

A 7 month female.

Complaining of: (history given by father)

Recurrent bouts of vomiting since 8 to 10 hours.

History of :

Accidental ingestion of foreign body (key) about 8 to 10 hours back.

$X$ ray Neck, Chest and Abdomen (AP \& Lateral View)

Shows an radio opaque foreign body (key) at the level of c6 and c7.

\section{Investigations}

Blood Routine: Normal

\section{Treatment}

hyphopharyngoscopy and removal of foreign body (key) done under I.V. sedation.

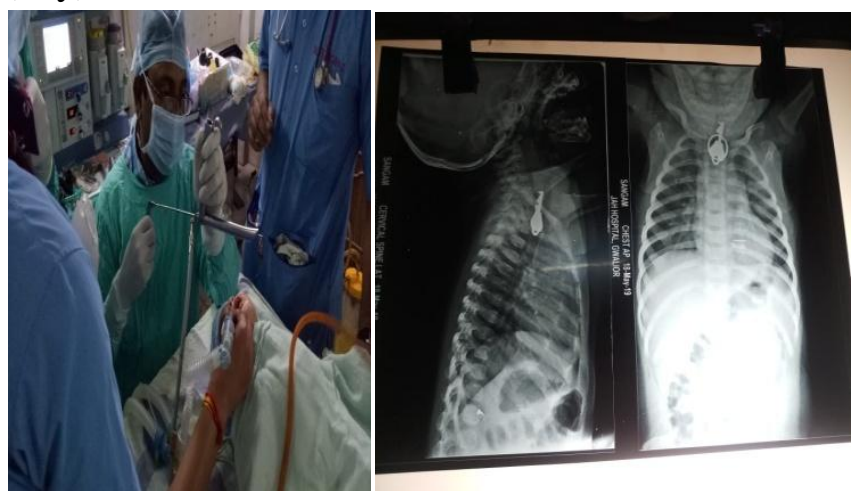




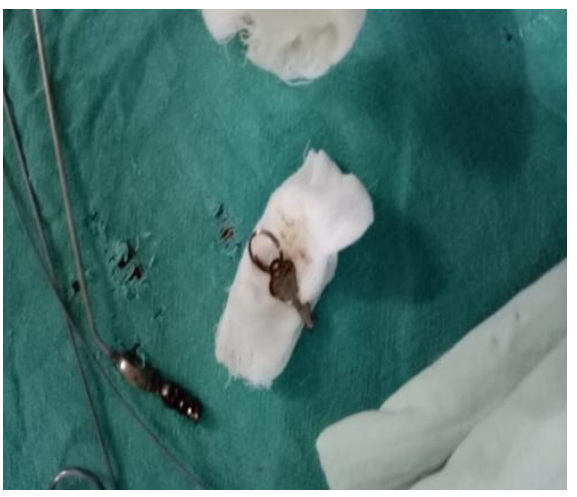

\section{Case 6}

A 4 year female.

Complaining of:

Pain in throat since 3 days.

History of :

Accidental ingestion of foreign body (coin) while playing.

Xray Neck, Chest and Abdomen (AP \& Lateral View)

Shows an circular radio-opaque foreign body (?coin) at the level of c6 and c7.

\section{Investigations}

Blood Routine: Normal

\section{Treatment}

Hypopharyngoscopy and removal of foreign body (coin) done under I.V. sedation.

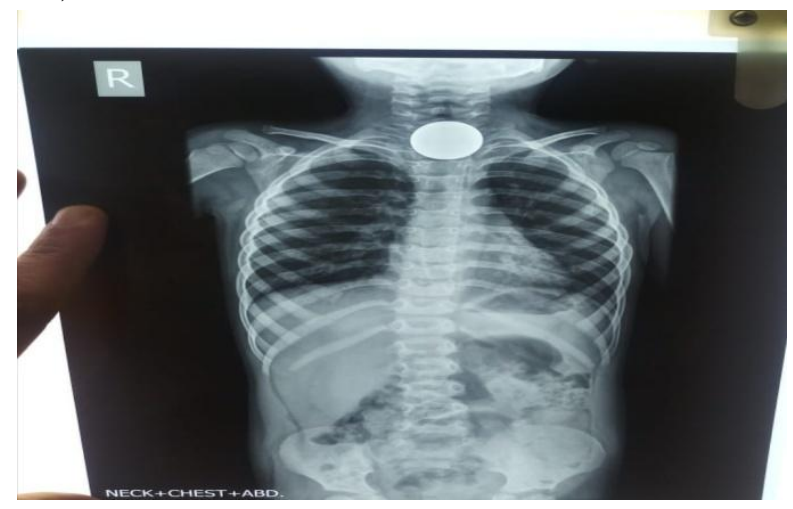

\section{Case 7}

A 42 year old female.

Complaining of:

Difficulty in swallowing since 3 hours

Foreign body sensation in throat since 3 hours

History of :

Accidental ingestion of ?fish bone during meal.

\section{Examination}

Ear: NAD
Nose: NAD

Mouth and Throat: NAD

Videolaryngoscopy:

Shows an foreign body (fish bone) in left pyriform fossa.

\section{Investigations:}

Blood Routine: Normal

\section{Treatment}

Direct laryngoscopy and removal of foreign body (fish bone) done under I.V. sedation.
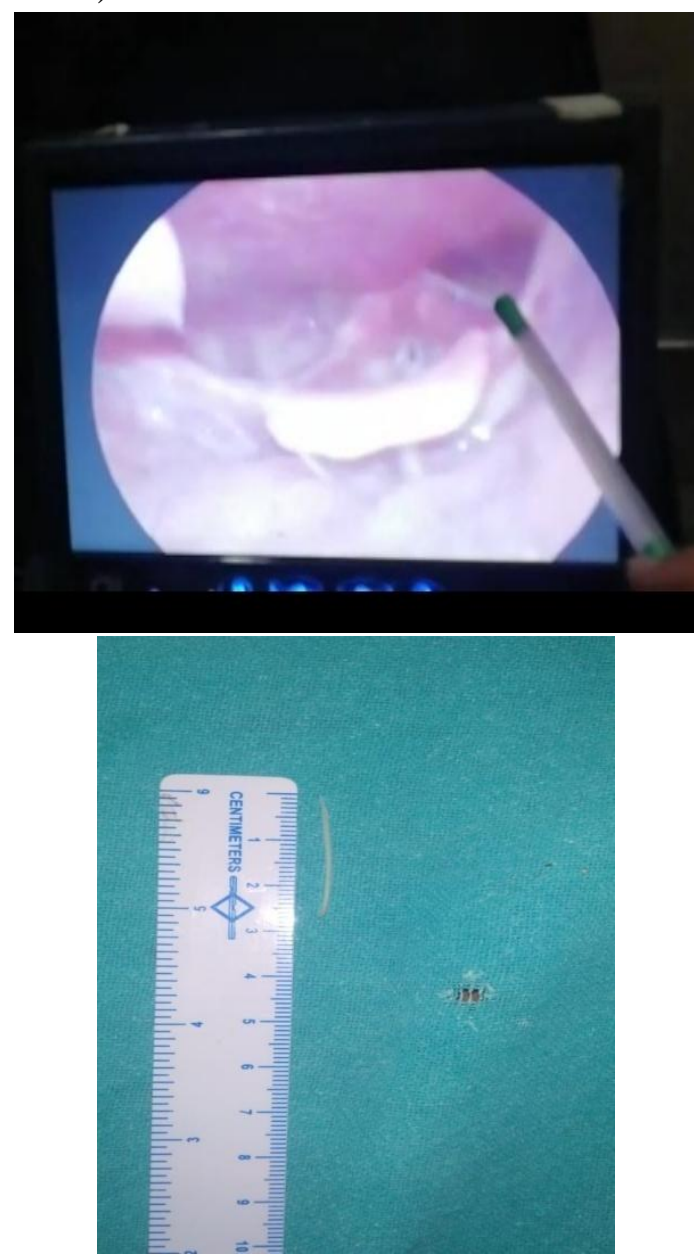

\section{Discussion}

Foreign body aspiration may present as a minor irritation or a life threatening problem ${ }^{[1,4]}$

$\mathrm{X}$-ray chest (CXRs) is commonly done but has only $67 \%$ diagnostic accuracy as concluded by a study ${ }^{[6]}$. Multi spiral CT \& VB is used to diagnose radiolucent $\mathrm{FB}$ missed on plain $\mathrm{X}$-ray. It reduces conventional bronchoscopy time, is non invasive and can go beyond the stenosed airway ${ }^{[7]}$.

Sharp objects are extremely challenging for endoscopic removal where the pointed end tends to engage (as seen in denture case). 
Thus, any child presenting with cough, vomiting, stridor and respiratory distress of acute onset should be suspected for FB aspiration unless proved otherwise. Parents usually have a tendency to put finger into child's mouth to remove a FB, which causes trauma, bleeding and pushes FB further into lower airways. This practice should therefore be discouraged.

\section{Conclusion}

Foreign body in ENT is the most common presentation in a wide range of age groups especially in paediatric patients. The most common age of foreign body presentation is $0-3$ years followed by 4-7 years due to the curious nature and development of pincer grasp in this age group. In general 3 years was the most common age of foreign body presentation. The most common time of presentation of foreign body was within the initial $0-8$ hours. The complications associated with foreign bodies can range from a minor infection or bleeding to death due to aspiration, thus carrying a significant mortality/ morbidity associated with them. The shape, size, types, site of lodgement, time of presentation of foreign body and socioeconomic status all have a role in their outcome and management. This necessitates an astute clinical judgement and prompt action in removal of foreign body so as to prevent any complication.

\section{References}

1. Scott-Browns's otorhinolaryngolog Head and Neck Surgery, Part-1, $7^{\text {th }}$ Edition, Chapter 92, Foreign bodies in ear and the aerodigestive tract in children, page no 1184.

2. Sharma HS, Sharma S. Management of laryngeal foreign bodies in children. J Accid Emerg Med. 1999;16(2):150-153. doi: 10.1136/emj.16.2.15

3. Kumar S, Al-Abri R, Sharma A, Al-Kindi H, Mishra P (2010) Management of pediatric tracheo bronchial foreign body aspiration. Oman Med J 25(4). doi:10.5001/omj.2010.99

4. Snow Jr. JB, Schild JA. Introduction to Peroral Endoscopy. In: Ballenger JJ, Snow Jr. JB, eds. Otolaryngology Head and Neck Surgery, $15^{\text {th }}$ edn. USA: Williams and Wilkins; PP:1189

5. Taksande A, Vilhekar K, Tyagi V. Uncommon foreign body aspiration in infant. Calicut Med J. 2010;8(2):e8.

6. Svedström E, Puhakka H, Kero P. How accurate is chest radiography in the diagnosis of tracheobronchial foreign bodies in children? Pediatr Radiol. 1989; 19(8):520-522. doi: 10.1007/BF02389562.

7. Lederman HM (2011) Airway foreign body imaging. Accessed 25 May 2011. 